\title{
Editorial: Transformative Urban Greening: Advancing Green Space Governance
}

\author{
Stephan Pauleit ${ }^{1 *}$, Rieke Hansen ${ }^{2}$ and Didit Okta Pribadi ${ }^{3}$ \\ ${ }^{1}$ School of Life Sciences, Chair for Strategic Landscape Planning and Management, Technical University of Munich, Munich, \\ Germany, ${ }^{2}$ Department of Open Space Development, Hochschule Geisenheim University, Geisenheim, Germany, ${ }^{3}$ Research \\ Center for Plant Conservation and Botanic Gardens, Indonesian Institute of Sciences, Bogor, Indonesia
}

Keywords: green infrastructure, nature-based solution (NBS), governance, transformation, participation, power structures, co-production

\section{Editorial on the Research Topic}

\section{Transformative Urban Greening: advancing green space governance}

Urban green and blue spaces can make a major contribution toward more livable, sustainable, and climate resilient cities. To better utilize the multiple potentials of green infrastructure and nature-based solutions, new modes of governance are required for the development, retrofitting, and maintenance of urban green and blue. However, the public domain with established separation of responsibilities and often dwindling resources for green space planning and management is challenged by these complex issues that require systemic transformations. Moreover, in many urban regions, green and blue spaces, including farmland and forests in the peri-urban, get lost or are impacted by ad hoc urban development and planning authorities lack leverages to steer urbanization processes toward sustainability.

Experience from previous larger research projects such as the EU FP7 funded project GREEN SURGE (2013-2017) (Pauleit et al., 2019) and the results from more recent projects within EU's Horizon 2020 on nature-based solutions (Bulkeley, 2020) suggest that there is a particular need for more scholarship on:

- Multi-level and multi-actor governance: i.e., integration of different sectors of the public domain into the strategic planning of green infrastructure and working across horizontal and vertical boundaries of decision-making; including new ways of funding for urban greening

Specialty section:

This article was submitted to

Urban Greening,

a section of the journal

Frontiers in Sustainable Cities

Received: 03 July 2021

Accepted: 26 August 2021

Published: 22 September 2021

Citation:

Pauleit S, Hansen R and Pribadi DO (2021) Editorial: Transformative Urban

Greening: Advancing Green Space

- Participation and cooperation: Developing inclusive and just planning and governance models and identifying the potential of co-created or citizen-led urban greening initiatives

- Power structures and mechanisms between governments, companies, and civil society in order to understand how those can be influenced.

Eight papers written by a distinguished set of authors were included in this article collection. These papers address not all but a surprisingly broad range of the themes mentioned above. Three of the paper are most closely linked to participation and cooperation, four address multi-level and multi-actor governance, even though often from a perspective of governmental stakeholders. One paper more specifically addresses the systemic understanding needed in order to be able to induce urban transformation. In addition, they provide a critical lens on the state and value of the concepts of urban green infrastructure and naturebased solutions-from planning to management in different regional and urban contexts. 
Challenges for participation and cooperation are highlighted with an emphasis on social justice. Based on a systematic literature review, it can be concluded that tools for participation need to be better adapted to the various needs of the local communities, specifically marginalized groups. In addition, there is a big deficit in knowledge on how to include civil society in green space management. A "cyclic process model for long-term participation in strategic management of urban green spaces" is suggested to guide such efforts (Fors et al.).

For co-produced urban green infrastructure, urban agriculture is another increasingly popular concept. Citizen-led urban agriculture offers the potential for stimulating economic growth and creating jobs, not least for migrants to the cities while simultaneously enhancing food security and it raises hope for solving pressing problems of rapid and unplanned urbanization in Africa, as shown by case studies. Yet, barriers initiatives include lack of supportive policies and need for resources for external stakeholders (Cilliers et al.). Requirements for the mainstreaming of more inclusive nature-based solutions (NBS) into planning were elaborated in a discussion paper (Basnou et al.). Such processes require not only experienced facilitators and the use of innovative participatory techniques but also a good understanding of local context with its specific social inequities, power relationships among actors and their preferences.

Several papers address the development of urban greening from the perspective of governmental or similar stakeholders with decision-making power. In Latin America, government-led initiatives for the development of green infrastructure prevail. A systematic literature review shows that they often are weakly resourced and fail to recognize specific challenges and conditions of informality and indigenous communities. As with some other papers in this article collection, the review thus highlights the need for green infrastructure development that better accounts for local contexts and needs and, to this end, better involves civil society, specifically the more marginalized and vulnerable groups (Breen et al.). Interviews with urban foresters in Northern America revealed the preference of urban foresters from different sectors in order to discuss differences in how citizens perceive urban forests and argue for co-governance approaches that should bring professional and public perception together (Sax et al.). In another paper, interviews with Scandinavian local governments shed light on how children are considered in green space planning and management. Despite awareness on children as a vulnerable group that benefits from urban green spaces, there are great differences in how explicitly children are considered in green space planning. Forms of co-governance were identified

\section{REFERENCES}

Bulkeley, H. (2020). Nature-Based Solutions Towards Sustainable Communities: Analysis of EU-Funded Projects. Luxembourg: Publications Office of the European Union. as an important success factor to better account for children in green space planning and management (Jansson et al.). Based on interviews with NBS practitioners involved in three major EU projects, O'Sullivan et al. show that NBS as a concept has the potential to facilitate communication with lay people on the benefits of nature when compared to more technical concepts such as ecosystem services. However, interviewees cautioned against a narrow and idealized representation of nature by NBS as a solution to every urban challenge-a promise unlikely to be kept and which may compromise the overall credibility of the entire concept in the longer run.

A more systemic perspective is applied for three case studies in Europe and Japan and reveals tensions between power structures on which the existence of NBS partially depends and overall ambitions to create more sustainable and just cities. Adoption of reflexive forms of NBS governance that promote arenas for learning and readjustment of institutions and practices are suggested (van der Jagt et al.). For considering urban greening as contribution to urban transformations, researchers should more strongly consider the complex systemic issues that contribute to unsustainable conditions and trajectories, from institutional path dependencies to social and economic injustices, and how those can be changed. Urban transitions literature as well as political ecology can provide additional lenses and conceptual underpinning for doing so (Wolfram et al., 2019; Hölscher and Frantzeskaki, 2021; Tzaninis et al., 2021).

In conclusion, the article collection "Transformative urban greening: advancing green space governance" provides a good cross-section of themes and issues related to the governance of green infrastructure and nature-based solutions. It demonstrates the viability of these and related concepts such as urban forestry and urban agriculture not only in the academic world but also in practice. The collection complements with a governance and management perspective the vast amount of scientific publications on the environmental functions and services of green infrastructure, often narrowly focusing on single aspects such as stormwater management. The need to better engage with vulnerable groups of society in decisionmaking and to encourage citizen-led initiatives in developing socially inclusive green infrastructure is clearly emphasized in this article collection. Reducing social and environmental injustices should therefore be key themes for the governance of green infrastructure.

\section{AUTHOR CONTRIBUTIONS}

All authors listed have made a substantial, direct and intellectual contribution to the work, and approved it for publication. 
reflections from the GREEN SURGE project. Urban Forestry Urban Greening 40, 4-16. doi: 10.1016/j.ufug.2018.10.006

Tzaninis, Y., Mandler, T., Kaika, M., and Keil, R. (2021). Moving urban political ecology beyond the 'urbanization of nature'. Prog Hum Geogr. 45, 229-252. doi: 10.1177/03091325209 03350

Wolfram, M., Borgström, S., and Farrelly, M. (2019). Urban transformative capacity: From concept to practice. AMBIO 48, 437-448. doi: 10.1007/s13280-019-01169-y

Conflict of Interest: The authors declare that the research was conducted in the absence of any commercial or financial relationships that could be construed as a potential conflict of interest.
Publisher's Note: All claims expressed in this article are solely those of the authors and do not necessarily represent those of their affiliated organizations, or those of the publisher, the editors and the reviewers. Any product that may be evaluated in this article, or claim that may be made by its manufacturer, is not guaranteed or endorsed by the publisher.

Copyright (c) 2021 Pauleit, Hansen and Pribadi. This is an open-access article distributed under the terms of the Creative Commons Attribution License (CC BY). The use, distribution or reproduction in other forums is permitted, provided the original author(s) and the copyright owner(s) are credited and that the original publication in this journal is cited, in accordance with accepted academic practice. No use, distribution or reproduction is permitted which does not comply with these terms. 